\title{
Sex, Race, and Consideration of Bariatric Surgery Among Primary Care Patients with Moderate to Severe Obesity
}

\author{
Christina C. Wee, MD, MPH' ${ }^{7}$, Karen W. Huskey, MPH' , Dragana Bolcic-Jankovic, MA ${ }^{2}$, \\ Mary Ellen Colten, $P h D^{2}$, Roger B. Davis, $S c D^{1}$, and MaryBeth Hamel, MD, MPH \\ 'Division of General Medicine and Primary Care, Department of Medicine, Beth Israel Deaconess Medical Center and Harvard Medical School, Boston, \\ MA, USA; ${ }^{2}$ Center for Survey Research, University of Massachusetts, Boston, MA, USA.
}

\begin{abstract}
BACKGROUND: Bariatric surgery is one of few obesity treatments to produce substantial weight loss but only a small proportion of medically-eligible patients, especially men and racial minorities, undergo bariatric surgery.

OBJECTIVE: To describe primary care patients' consideration of bariatric surgery, potential variation by sex and race, and factors that underlie any variation.

DESIGN, SETTING, AND PATIENTS: Telephone interview of 337 patients with a body mass index or BMI > $35 \mathrm{~kg} / \mathrm{m}^{2}$ seen at four diverse primary care practices in Greater-Boston.
\end{abstract}

MEASUREMENTS: Patients' consideration of bariatric surgery.

RESULTS: Of 325 patients who had heard of bariatric surgery, $34 \%$ had seriously considered surgery. Men were less likely than women and African Americans were less likely than Caucasian patients to have considered surgery after adjustment for sociodemographics and BMI. Comorbid conditions did not explain sex and racial differences but racial differences dissipated after adjustment for quality of life (QOL), which tended to be higher among African American than Caucasian patients. Physician recommendation of bariatric surgery was independently associated with serious consideration for surgery [OR 4.95 (95 \% CI 2.81-8.70)], but did not explain variation in consideration of surgery across sex and race. However, if recommended by their doctor, men were as willing and African American and Hispanic patients were more willing to consider bariatric surgery than their respective counterparts after adjustment. Nevertheless, only $20 \%$ of patients reported being recommended bariatric surgery by their doctor and African Americans and men were less likely to receive this recommendation; racial differences in being recommended surgery were also largely explained by differences in QOL. High perceived risk to bariatric surgery was the most commonly cited barrier; financial concerns were uncommonly cited.

LIMITATIONS: Single geographic region; examined consideration and not who eventually proceeded with bariatric surgery.

CONCLUSION: African Americans and men were less likely to have considered bariatric surgery and were less likely to have been recommended surgery by their

Received February 7, 2013

Revised June 18, 2013

Accepted August 16, 2013

Published online September 19, 2013 doctors. Differences in how obesity affects QOL appear to account for some of these variations. High perceived risk rather than financial barrier was the major deterrent for patients.

KEY WORDS: obesity; bariatric surgery; race; sex; physician counseling. J Gen Intern Med 29(1):68-75

DOI: $10.1007 / \mathrm{s} 11606-013-2603-1$

(C) Society of General Internal Medicine 2013

\section{INTRODUCTION}

Bariatric surgery is one of few obesity treatments shown to produce substantial long-term weight loss. ${ }^{1,2}$ Nevertheless, although well over 100,000 Americans undergo bariatric surgery each year, ${ }^{3}$ this figure represents only a small fraction of medically eligible patients. ${ }^{4}$ African Americans, men, and the socioeconomically disadvantaged in particular are underrepresented among those who undergo these procedures. ${ }^{5,6}$ Extrapolation of prior studies suggest that Caucasian Americans are twice as likely as African Americans and women are several times more likely than men to undergo bariatric surgery. 5,6

The factors underlying such large demographic variations in the use of bariatric surgery are unclear. Despite its rising popularity, bariatric surgery is neither risk-free nor universally effective. $^{2,7-12}$ Data suggest mortality risks range from less than $1 \%$ to as high as $5 \%$ in some high risk groups ${ }^{2,10,11}$ Risk for serious complications and revisional surgery can be as high as $20 \%{ }^{1,2}$ High quality long-term data on diverse populations in the U.S are lacking. However, data from European populations suggest that while initial weight losses can be impressive within the first year or two after surgery, recidivism occurs in a large subset of patients. ${ }^{7,12}$ Nevertheless, bariatic surgery leads to improvement in comorbidities especially diabetes, ${ }^{13,14}$ even after accounting for weight regain. ${ }^{7,12,15}$

Bariatric surgery's associated risks and its limited long-term data in diverse U.S. populations may lead to ambivalence among some clinicians about routinely recommending this intervention as a means to control weight. Moreover, patient preferences for different weight loss approaches especially for 
potentially risky interventions are poorly understood. Although obesity has profound medical and psychosocial consequences, there is some evidence to suggest that these consequences may vary across different groups. ${ }^{16-21}$ For example, observational studies suggest that the mortality risk associated with obesity may be attenuated in African Americans relative to Caucasian Americans; men and African Americans may also perceive less social stigma and adverse quality of life consequences than women and Caucasian Americans and may have lower weight loss goals. ${ }^{16-21}$ Thus, the motivation to seek potentially risky weight loss treatments such as bariatric surgery may differ among different subgroups of patients.

In this context, we interviewed over 300 sociodemographically diverse primary care patients with moderate to severe obesity to understand patients' willingness to consider bariatric surgery and the factors associated with this willingness. We were particularly interested in whether there were differences across sex and race and in uncovering potential factors that might underlie these differences.

\section{METHODS}

\section{Study Sample, Recruitment, and Data Collection}

We conducted a telephone interview of 337 patients recruited from 4 primary care practices in greater-Boston: a large hospital-based academic practice, a suburban practice in an affluent neighborhood, a practice located in a working class community, and a community health center in a socioeconomically disadvantaged neighborhood.

We screened appointment logs and medical records and identified a complex random sample of potentially eligible patients, oversampling for both African American and Hispanic patients. ${ }^{22}$ Sampling weights were created so that our estimates can be adjusted to reflect the racial and ethnic distribution of the practices from which patients were recruited. To be eligible, patients had to have been seen in the practice within the preceding year, be aged 18 to 65 years at screening, speak English or Spanish, have a body mass index (BMI) of $35 \mathrm{~kg} / \mathrm{m}^{2}$ or higher (minimum BMI requirement for bariatric surgery), and have the permission of their physician for us to contact the patient. Patients were excluded if they did not have a valid address or telephone number, if they had terminal or serious life-limiting illness or severe unstable psychiatric illness (including active eating disorders) for which the interview might cause harm. We also excluded two patients who had undergone bariatric surgery in the past. We estimated our response rate to be $58 \%$ of those eligible (see appendix).

All participants underwent a 45-60 min telephone interview conducted in either English or Spanish by a trained interviewer.

\section{Measures}

Body Weight and Perceptions of Weight. We asked patients to report their weight and height and used these data to calculate BMI. $^{23}$ We also asked about patients' overall perception of their weight ("How would describe your current weight?"...) and the risk their weight posed to their health (In your opinion, how much of a health risk is it being at your current weight? 1 = extremely high, 5 = no risk). We then asked for patients' ideal weight ("If you could be any weight, how much would you like to weigh?) and calculated their ideal weight loss in terms of the percent weight loss necessary to achieve their ideal weight. Finally, we asked participants "... what is the least amount of weight you could lose from your current weight and still get any health benefits...?"

Patient Perceptions and Physician Recommendations Regarding Bariatric Surgery. We next asked patients a series of questions about bariatric surgery such as if they had ever heard of "bariatric or weight loss surgery"; their sources of information about surgery including whether they discussed it with their doctor; whether they had seriously considered undergoing surgery; whether their doctor had recommended it; and whether they would consider undergoing bariatric surgery if their doctor recommended it. Among those who would not consider surgery even if their doctor recommended it, we asked for the primary reason (e.g. too much weight loss, don't know enough about it, don't medically qualify, too expensive/ insurance reasons, too risky etc.)

Quality of Life. We assessed quality of life (QOL) using the Impact of Weight on Quality of Life-lite (IWQOL-lite). ${ }^{24}$ The IWQOL-lite is a 31-item instrument developed to capture 5 domains specific to obesity ${ }^{24}$ — physical function, self-esteem, sexual life, public distress and work. Respondents are given a series of statements that begin with "Because of my weight..." and then asked to rate whether the statement is "always true, usually true, sometimes true, rarely true or never true." A global score ranging from 0 to 100 is then derived using standard methods. ${ }^{24}$ Higher scores reflect better quality of life.

Clinical and Demographic Factors. We asked about participants' demographic characteristics including age, sex, race/ethnicity, and education. In addition, we abstracted information about patients' chronic health conditions including common conditions associated with obesity. 


\section{Data Analysis}

We used descriptive statistics to characterize our sample overall and according to sex and race. In particular, we characterized the proportion of patients across our 3 outcomes of interest: 1) whether patients had ever seriously considered undergoing bariatric surgery, 2) whether they received recommendation from their doctor to undergo bariatric surgery, and 3) whether patients would consider undergoing bariatric surgery if recommended to do so by their physician.

We then developed a series of multivariable logistic regression models to examine the relationship between sex, race, other factors, and our three outcomes. Because we were both interested in not only examining the contributions of different factors to these outcomes but importantly, whether these factors explained or mediated any potential variation by sex and race, we conducted a series of hierarchical models. For each outcome, we first developed a parsimonious model adjusting for BMI, recruitment site, and basic demographic variables including age, sex, and race. To test whether social disadvantage accounted for any observed variation by sex or race, we next adjusted for education. Using a similar approach we then sequentially adjusted for comorbid conditions followed by quality of life score, and patients' perceptions and goals. The latter category included patients' perception of their weight as a health risk, the minimum weight loss they perceived as necessary to derive any health benefit and their ideal weight loss goal. The order in which factors were added to the model were in part driven by where along the causal pathway factors might lie. We used forward selection $(p<$ $0.10)$ and backward elimination procedures $(p<0.05)$ to identify comorbid conditions that were significantly associated with our outcomes. For models related to the first outcome, we also separately considered physician as a source of patient information and physician recommendation for surgery as two additional explanatory factors.

We weighted our sample to reflect our complex random sampling design.

\section{RESULTS}

Table 1 presents the characteristics of our sample. The majority of patients were women. By design, more than half the sample were Non-White. Several patient characteristics differed by sex and race. In particular, QOL scores were lower in women than men and higher among African American than Caucasian patients even after accounting for

Table 1. Sample Characteristics

\begin{tabular}{|c|c|c|c|c|c|c|}
\hline & Overall sample & Men & Women & White & $\mathbf{A A}$ & Hispanic \\
\hline Sample size & 337 & 104 & 233 & 118 & 119 & 83 \\
\hline \multicolumn{7}{|l|}{ Proportion of sample } \\
\hline Unweighted percent & 100 & 31 & 69 & 35 & 36 & 25 \\
\hline Weighted percent & 100 & 32 & 68 & 50 & 36 & 10 \\
\hline Mean age & 48.7 & 46.8 & $49.6 *$ & 51.0 & $47.0 *$ & 43.6* \\
\hline \multicolumn{7}{|l|}{ Education } \\
\hline HS diploma, GED, or less & 36 & 31 & 38 & 23 & $44^{*}$ & $57 *$ \\
\hline Some college or 2 -year degree & 29 & 29 & 29 & 26 & $32 *$ & $31 *$ \\
\hline 4 year college diploma, or more & 35 & 40 & 33 & 51 & $24 *$ & $12 *$ \\
\hline \multicolumn{7}{|l|}{ Income } \\
\hline$\$ 20,000$ or less & 24 & 12 & $29 *$ & 14 & $29 *$ & $46 *$ \\
\hline$\$ 20,001-\$ 40,000$ & 36 & 25 & $40 *$ & 25 & $49 *$ & $42 *$ \\
\hline$\$ 40,001-\$ 80,000$ & 19 & 30 & $14 *$ & 23 & $16 *$ & $10 *$ \\
\hline Over $\$ 80,000$ & 22 & 32 & $17 *$ & 38 & $5 *$ & $1 *$ \\
\hline \multicolumn{7}{|l|}{ IWQOL-lite (0-100) } \\
\hline Overall summary & 70.1 & 75.3 & $67.7 *$ & 66.1 & $75.6 *$ & 67.7 \\
\hline \multicolumn{7}{|l|}{ Comorbidities } \\
\hline Cardio-/cerebro-vascular disease & 7 & 11 & $5^{*}$ & 9 & $4 *$ & 7 \\
\hline Asthma, sleep apnea & 35 & 30 & $38 *$ & 36 & 37 & 42 \\
\hline Depression, anxiety & 44 & 34 & $49 *$ & 52 & $35 *$ & 41 \\
\hline Arthritis, back pain & 41 & 36 & $44 *$ & 38 & 43 & $51 *$ \\
\hline Diabetes & 20 & 21 & 20 & 19 & 22 & 22 \\
\hline High blood pressure & 50 & 59 & $45^{*}$ & 50 & 50 & 41 \\
\hline $\begin{array}{l}\text { Other disease (high cholesterol, } \\
\text { GERD, gall bladder problems, } \\
\text { serious liver disease) }\end{array}$ & 46 & 52 & $43 *$ & 52 & $40 *$ & 45 \\
\hline
\end{tabular}

Weighted samples were used to account for oversampling of nonwhites during recruitment

*And results delineated in bold indicate statistically significant differences across the variable by gender or race at P<0.05. We used T-tests to compare differences in means for continuous variables and global Wald Chi-square test for differences in proportions categorical variables except for racelethnicity where separate chi-square tests were conducted to differences between White and AA and between White and Hispanic patients 
differences in age and BMI (data not shown). Table 2 presents patients' baseline body weight and their preferences and perceptions of weight and weight loss. After adjustment for age, BMI, and recruitment site, women desired a $7.6 \%$ higher percent weight loss than men $(p<$ 0.001 ) whereas Caucasian patients reported a $3.7 \%$ higher percent weight loss than African American patients ( $p=$ $0.01)$.

Of 337 patients, 325 reported that they had heard of bariatric surgery. Of these patients, 120 (37\% weighted) reported that they had seriously considered undergoing bariatric surgery. Men were significantly less likely than women to have considered surgery but African Americans were no less likely than Caucasians to have considered bariatric surgery prior to adjustment for potential confounders (see Table 2). Table 3 presents the adjusted association between sex and race and the likelihood that patients had considered bariatric surgery. Table 3 also presents other significant correlates and the role that these factors might play in explaining any observed differences by sex and race. After initial adjustment for age, BMI, and study site, African Americans were significantly less likely than Caucasian patients, and men were significantly less likely than women to have seriously considered undergoing surgery (Table 3, Model 1). Additional adjustment for education modestly attenuated differences by race but not by sex. Differences in comorbid conditions did not account for either gender or racial differences (Table 3, Model 3).
However, once we adjusted for QOL scores, racial (but not gender) differences dissipated-suggesting that racial differences in having considered surgery was largely explained by racial differences in obesity-related QOL (Table 3, model 4). Having a lower ideal weight (higher ideal weight loss) was also associated with having considered bariatric surgery and appeared to partially explain observed gender differences. While physician recommendation was a strong independent correlate of patients considering surgery, it did not explain gender and racial variation in our outcome.

Only $20 \%$ of patients reported ever having received a recommendation to undergo bariatric surgery by their physician, whereas $35 \%$ reported receiving information about surgery from their doctors; men and African Americans were significantly less likely to be recommended surgery by their doctor even though they were as or more likely to report receiving information about bariatric surgery from their doctor than their respective counterparts (Table 2). Differences in physician recommendation by sex and race persisted but were no longer statistically significant after adjustment for age, BMI, site, education and comorbid conditions; the odds ratio (OR) was 0.62 (95\% CI 0.36$1.08)$ for men compared to women and $0.58(0.31-1.07)$ for African American compared to Caucasian patients. When we additionally adjusted for QOL, these differences were substantially attenuated with ORs of $0.86(0.47-1.56)$ for men and 0.88 (0.45-1.73) for African American.

Table 2. Perspectives of Primary Care Patients Regarding Body Weight and Bariatric Weight Loss Surgery (WLS) Prior to Adjustment,\%

\begin{tabular}{|c|c|c|c|c|c|c|}
\hline & Overall sample & Men & Women & White & $\mathbf{A A}$ & Hispanic \\
\hline Sample size & 337 & 104 & 233 & 118 & 119 & 83 \\
\hline Current weight in lbs (BMI) & $256.8(40.7)$ & $282.0(39.6) *$ & $245.0(41.2)^{*}$ & $264.1(41.1)$ & $250.5 *(40.4)$ & $247.9 *(40.9)$ \\
\hline Ideal weight in lbs (BMI) & $171.9(27.0)$ & $202.8(28.4) *$ & $156.7 *(26.4)$ & $172.9(26.7)$ & $171.9(27.5)$ & $164.4(27.1)$ \\
\hline $\begin{array}{l}\text { Weight loss required to achieve } \\
\text { perceived ideal weight, } \\
\% \text { of baseline weight }\end{array}$ & 33 & 27* & $35^{*}$ & 34 & 32 & 33 \\
\hline $\begin{array}{l}\text { Minimum weight loss satisfactory } \\
\text { to patients, \% of baseline weight }\end{array}$ & 24 & 18 & $27^{*}$ & 24 & 25 & 26 \\
\hline $\begin{array}{l}\text { Ever seriously considered WLS, } \\
\%\end{array}$ & 34 & 22 & $40 *$ & 34 & 33 & $46^{*}$ \\
\hline $\begin{array}{l}\text { PCP provided info about WLS, } \\
\%\end{array}$ & 35 & 35 & 35 & 28 & $45^{*}$ & $52 *$ \\
\hline $\begin{array}{l}\text { Doctor recommended WLS, \% } \\
\text { Would consider WLS if doctor } \\
\text { recommended, \% }\end{array}$ & 20 & 14 & $22 *$ & 22 & 16 & 22 \\
\hline Yes & 46 & 46 & 46 & 44 & 46 & $66 *$ \\
\hline $\mathrm{No}^{\dagger}$ & 54 & 54 & 54 & 56 & 54 & $34 *$ \\
\hline It would cause too much weight loss & 0.2 & 0 & 0.4 & 0 & 0 & 4 \\
\hline Don't know enough about WLS & 1 & 0 & 1 & 0 & 3 & 0 \\
\hline Don't medically qualify & 2 & 0 & 3 & 3 & 0 & 0 \\
\hline $\begin{array}{l}\text { Try non-surgical weight treatment } \\
\text { first }\end{array}$ & 17 & 16 & 17 & 17 & 18 & 15 \\
\hline Too expensive or insurance issues & 1 & 3 & 0 & 2 & 0 & 0 \\
\hline Too risky & 39 & 46 & 37 & 36 & 42 & 39 \\
\hline Not sure that it works & 1 & 1 & 1 & 0 & 3 & 4 \\
\hline Too many side effects & 4 & 1 & 5 & 3 & 4 & 7 \\
\hline Other & 35 & 34 & 35 & 39 & 31 & 31 \\
\hline
\end{tabular}

Results delineated in bold and by * refer to statistically significant differences at $p<0.05$ across sex or racelethnicity as appropriate (Wald Chisquare test for difference in proportions, t-test for difference in means)

'Individual reasons for not considering WLS were not tested for significant differences across sex or race/ethnicity 
Table 3. Relationship Among Race, Sex, and Other Factors and Patients' Consideration of Bariatric Surgery

\begin{tabular}{|c|c|c|c|c|c|c|}
\hline \multirow[t]{2}{*}{ Correlates } & \multicolumn{6}{|c|}{ Odds ratio (95\% CI) of having considered WLS } \\
\hline & $\begin{array}{l}\text { Model 1 } \\
\text { (age + BMI) }\end{array}$ & $\begin{array}{l}\text { Model 2 } \\
\text { (model 1 + } \\
\text { education) }\end{array}$ & $\begin{array}{l}\text { Model 3 } \\
\text { (model 2 + } \\
\text { comorbidity) }\end{array}$ & $\begin{array}{l}\text { Model 4 } \\
\text { (model 3 + } \\
\text { QOL) }\end{array}$ & $\begin{array}{l}\text { Model 5 } \\
\text { (model 4 + } \\
\text { patient goals) }\end{array}$ & $\begin{array}{l}\text { Model 6 } \\
\text { (model 5 + } \\
\text { MD Rec.) }\end{array}$ \\
\hline Model C-statistic & 0.73 & 0.75 & 0.77 & 0.81 & 0.81 & 0.83 \\
\hline \multicolumn{7}{|l|}{ Race/ethnicity } \\
\hline White & 1.00 & 1.00 & 1.00 & 1.00 & 1.00 & 1.00 \\
\hline AA & $0.58(0.38,0.90)$ & $0.64(0.41,1.01)$ & $0.64(0.40,1.03)$ & $1.18(0.68,2.05)$ & $1.33(0.73,2.43)$ & $1.31(0.71,2.45)$ \\
\hline Hispanic & $1.34(0.75,2.41)$ & $1.56(0.85,2.87)$ & $1.74(0.92,3.27)$ & $1.67(0.82,3.42)$ & $1.50(0.69,3.26)$ & $1.58(0.71,3.51)$ \\
\hline Other & $0.67(0.28,1.66)$ & $0.78(0.31,1.96)$ & $0.71(0.27,1.89)$ & $1.57(0.47,5.22)$ & $1.94(0.49,7.73)$ & $1.48(0.36,6.16)$ \\
\hline \multicolumn{7}{|c|}{ 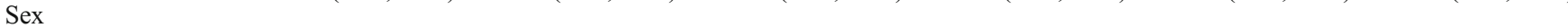 } \\
\hline Men & $0.38(0.26,0.57)$ & $0.38(0.26,0.57)$ & $0.29(0.19,0.45)$ & $0.29(0.17,0.48)$ & $0.49(0.29,0.84)$ & $0.41(0.24,0.72)$ \\
\hline Women & 1.00 & 1.00 & 1.00 & 1.00 & 1.00 & 1.00 \\
\hline Age & $0.98(0.96,0.99)$ & $0.98(0.97,1.00)$ & $0.96(0.94,0.98)$ & $0.94(0.92,0.96)$ & $0.93(0.91,0.96)$ & $0.93(0.91,0.95)$ \\
\hline BMI & $1.15(1.12,1.19)$ & $1.16(1.12,1.20)$ & $1.14(1.10,1.18)$ & $1.09(1.05,1.13)$ & $1.09(1.04,1.14)$ & $1.04(0.99,1.09)$ \\
\hline \multicolumn{7}{|l|}{ Education } \\
\hline$\leq$ High school & - & 1.00 & 1.00 & 1.00 & 1.00 & 1.00 \\
\hline$\overline{\text { Some college }}$ & & $2.15(1.42,3.26)$ & $2.37(1.54,3.65)$ & $2.00(1.25,3.21)$ & $2.46(1.48,4.09)$ & $2.02(1.19,3.41)$ \\
\hline 4 year college + & & $1.59(1.00,2.51)$ & $1.70(1.05,2.75)$ & $1.32(0.77,2.26)$ & $1.11(0.62,1.99)$ & $1.08(0.59,1.98)$ \\
\hline \multicolumn{7}{|l|}{ Comobidities $^{\wedge}$} \\
\hline Heart disease & - & - & $2.36(1.25,4.46)$ & - & - & - \\
\hline Hypertension & - & - & $2.62(1.77,3.88)$ & $2.90(1.89,4.46)$ & $3.61(2.24,5.82)$ & $3.17(1.93,5.21)$ \\
\hline Depression/anxiety & - & - & $1.63(1.15,2.31)$ & $1.53(1.03,2.26)$ & $1.46(0.95,2.25)$ & $1.45(0.92,2.28)$ \\
\hline $\begin{array}{l}\text { Obesity-specific } \\
\text { QOL, per } 10 \text { point } \\
\text { increase in IWQOL- } \\
\text { lite score }\end{array}$ & - & - & - & $0.69(0.62,0.78)$ & $0.61(0.53,0.70)$ & $0.68(0.59,0.78)$ \\
\hline $\begin{array}{l}\text { Ideal weight loss (\% } \\
\text { of body weight) }\end{array}$ & - & - & - & - & $1.02(1.00,1.04)$ & $1.02(1.00,1.04)$ \\
\hline $\begin{array}{l}\text { Physician } \\
\text { recommendation }\end{array}$ & - & - & - & - & - & $4.95(2.81,8.70)$ \\
\hline
\end{tabular}

All models adjusted for variables with estimates presented in the relevant columns. In Models 3, 4, and 5, other comorbidities tested (pulmonary disease, arthritis/back pain, diabetes, high cholesterol/GERD/gall bladder disease/serious liver damage) were not included in the model if they did not statistically significance; heart disease became non-significant after adjustment for QOL and was not included in Models 4, 5, and 6. In addition, Models 5 and 6 were also adjusted for patients' perception of the health risk posed by their weight because this factor confounded the association between patients' weight loss and the outcomes

Approximately half the patients in our study would consider undergoing bariatric surgery if recommended to do so by their doctor (see Table 2). Interestingly, African American patients were no less likely and Hispanics were more likely than Caucasian patients to consider bariatric surgery with physician recommendation; after adjustment, African American patients were more likely to consider surgery than Caucasian patients. Similarly, men were as likely as women to be willing to consider surgery in this context before (Table 2) and after adjustment (Table 4). Age, education, QOL and the minimum level of weight loss considered satisfactory by the patient were all also associated with consideration of surgery upon physician advice (Table 4). After full adjustment, diabetes was the only comorbid condition associated with a higher likelihood of consideration of surgery. Patients with asthma or obstructive sleep apnea and arthritis or back pain were less likely to consider surgery. Interestingly, while higher BMI was associated with being more likely to consider surgery after initial adjustment, those with higher BMI were actually less likely to consider surgery once comorbidities and QOL were accounted for. The most common reported deterrent to surgery was the perception that surgery was "too risky" (Table 2). Lack of information or financial or insurance coverage concerns were not perceived as major barriers.

\section{DISCUSSION}

In our survey study of over 300 primary care patients with moderate to severe obesity, we found that men were less likely than women and African Americans were less likely than Caucasian primary care patients to have seriously considered bariatric surgery after accounting for sociodemographic factors and comorbid conditions. Much of the observed differences by race, however, appeared to be explained by higher QOL scores among African American relative to Caucasian patients with obesity. In contrast, differences by sex were partially attributable to greater weight loss desired by women than men. When asked whether patients would seriously consider bariatric surgery if recommended by their doctor, almost half of all patients responded affirmatively. Moreover, men and African Americans were no less likely than their respective 
Table 4. Patients' Willingness to Consider Bariatric Surgery if Advised to do so by Their Doctor

\begin{tabular}{|c|c|c|}
\hline \multirow[t]{2}{*}{ Correlates } & \multicolumn{2}{|c|}{ Odds ratio $(95 \%$ CI $)$} \\
\hline & Initial model & Final model \\
\hline Model C-statistic & 0.65 & 0.76 \\
\hline \multicolumn{3}{|l|}{ Race/ethnicity } \\
\hline White & 1.00 & 1.00 \\
\hline AA & $1.30(0.86,1.96)$ & $2.14(1.28,3.59)$ \\
\hline Hispanic & $3.04(1.73,5.34)$ & $4.22(2.00,8.89)$ \\
\hline Other & $0.76(0.32,1.80)$ & $0.24(0.06,0.97)$ \\
\hline \multicolumn{3}{|l|}{ Sex } \\
\hline Men & $0.95(0.68,1.32)$ & $1.50(0.95,2.37)$ \\
\hline Women & 1.00 & 1.00 \\
\hline Age & $0.98(0.97,0.99)$ & $0.95(0.94,0.97)$ \\
\hline BMI & $1.02(1.00,1.05)$ & $0.92(0.88,0.96)$ \\
\hline \multicolumn{3}{|l|}{ Education } \\
\hline HS diploma, GED, or less & 1.00 & 1.00 \\
\hline Some college & $1.20(0.82,1.76)$ & $1.64(1.02,2.64)$ \\
\hline 4 year college + & $2.50(1.65,3.77)$ & $2.57(1.55,4.25)$ \\
\hline \multicolumn{3}{|l|}{ Comobidities $^{\wedge}$} \\
\hline Asthma/apnea & - & $0.49(0.33,0.73)$ \\
\hline Diabetes & & $1.95(1.17,3.25)$ \\
\hline Arthritis/back pain & & $0.34(0.23,0.50)$ \\
\hline $\begin{array}{l}\text { Obesity-specific QOL, per } 10 \\
\text { point increase in IWQOL-lite } \\
\text { score }\end{array}$ & - & $0.65(0.57,0.73)$ \\
\hline $\begin{array}{l}\text { Minimum weight loss } \\
\text { satisfactory to patient (\% } \\
\text { baseline bodv weight) }\end{array}$ & & $1.04(1.02,1.06)$ \\
\hline
\end{tabular}

All models adjusted for variables with estimates presented in the relevant columns; the final model was additionally adjusted for patients' perception of the health risk posed by their weight because this factor confounded the association between patients' minimum satisfactory weight loss and the outcome. In the final model, comorbidities tested (pulmonary disease, arthritis/back pain, diabetes, high cholesterol/GERD/gall bladder disease/serious liver damage) were not included if they were not statistically significant

counterparts to consider their doctor's advice; after accounting for comorbid conditions and QOL, African American and Hispanic patients were actually more likely to report willingness to seriously consider bariatric surgery if recommended by their doctor. Interestingly, both men and African American patients were less likely to receive physician recommendation to undergo bariatric surgery.

Previous work suggests that obesity affects individuals and populations in varying ways and racial and ethnic minorities are less likely to undergo bariatric surgery. ${ }^{25}$ Few studies have systematically examined, however, the factors that underlie variation in the adoption of bariatric surgery. While it is generally assumed that much of the variation reflects socioeconomic barriers to some extent, our findings do not support this assumption at least from the patients' perspective. Financial or insurance coverage concerns were rarely cited as a barrier in our study and while those who were less educated were less likely to have considered surgery, this association did not contribute to observed racial differences. Rather, high perceive risk was the major deterrent reported by patients.

Our findings are consistent with other studies that suggest that men and African American patients on average have higher self-reported QOL than women and Caucasian patients, ${ }^{16,19-21}$ and that weight loss treatment seeking patients tend to have poorer QOL than obese persons in the community. ${ }^{26}$ Our study goes one step further by suggesting that this higher QOL appears to explain to a large extent why African American patients may not consider bariatric surgery to the same degree as Caucasian patients. QOL differences may also explain why physicians may be less likely to recommend bariatric surgery to African American patients with obesity. Interestingly, differences in QOL did not explain gender differences in consideration for bariatric surgery but may influence whether physicians recommend surgery to men patients.

Earlier studies have suggested that African Americans may have higher ideal body weights and desire less weight loss than their Caucasian counterpart. ${ }^{20,21,27}$ While our adjusted findings suggest modest differences in perceived ideal weight loss between African American and Caucasian patients, these differences did not explain observed racial variation in considering bariatric surgery. In contrast, women in general desired greater weight loss than men and this difference did partially explain why women were more likely to consider bariatric surgery than men.

Our study suggests that men and African American and Hispanic patients appear to be receptive to bariatric surgery if these procedures are recommended by their doctor. Whether physicians should recommend these procedures uniformly to all patients who medically qualify remains unclear. While there is compelling long-term evidence that the Roux-en-Y Gastric Bypass remains effective, much of this evidence is drawn from non-African American populations and rigorous longer-term (greater than 5 years) evidence on the effectiveness of less invasive procedures such as the laparoscopic gastric banding are still lacking. ${ }^{7,8}$ Moreover, limited available data suggest that bariatric surgery may be less effective among racial minorities. ${ }^{28}$ There is less dispute about the effectiveness of bariatric surgery in men; however, the perioperative risk may be slightly higher than in women. ${ }^{10,29}$ Nevertheless, improved discussions about the risks and benefits of bariatric surgery are likely warranted especially since high perceived risk is the most common deterrent cited by patients. Whether the level of risk perceived by patients in our study was appropriate was not explored.

Not surprisingly, our study also found that younger patients, those with certain comorbidities especially diabetes, and those 
with lower QOL were more likely to have considered bariatric surgery. Interestingly, patients with higher BMI were more likely to have considered bariatric surgery if recommended by a physician but were actually less likely to do so once comorbidities and QOL considerations were accounted for, suggesting perhaps that obese patients with good QOL and low illness burden may not be responsive to physician's advice to consider surgery.

Our results must be interpreted in the context of its limitations. Patients were from practices in Greater-Boston and our results may not generalize to other parts of the U.S. Our sample size was also relatively modest and we may not have been adequately powered to detect small but clinically meaningful differences in our outcomes of interests. We were not able to adjust for the language in which the interview was conducted because not all sites had nonEnglish-speaking patients of Hispanic ethnicity. We based eligibility for our study and for bariatric surgery primarily on a BMI of 35 ; it is possible that not all study patients would have met the National Institutes of Health eligibility criteria for bariatric surgery, particularly for those with a BMI between 35 and 40. Finally, many of our conclusions are inferential. For example we did not explicitly ask whether patients would make decisions about bariatric surgery based on QOL considerations. It is possible that patients' QOL reflected severity of illness not adequately captured by our adjustment for comorbid conditions.

In summary, our study suggests that while obese men and African American primary care patients are less likely to have considered bariatric surgery than women and Caucasian patients, they are as if not more likely to consider surgery if the treatment is recommended by their doctor. Obesity-related QOL appeared to be an important factor for whether patients consider bariatric surgery and to which patients physicians recommend surgery. Quality of life considerations also appear to explain racial differences in whether patients have bariatric surgery and physician recommendation. In contrast, gender preferences in ideal weight loss partially explained greater predilection among women than men to consider surgery. The perceived risk of surgery rather than economic barriers was the most important deterrent cited by patients.

ACKNOWLEDGMENT: The study was funded by a grant from the National Institutes of Health (RO1DK073302, PI Wee). Dr. Wee is also supported by a NIH Midcareer Mentorship Award (K24DK087932). The funder had no role in the design and conduct of the study; collection, management, analysis, and interpretation of the data; and preparation, review, or approval of the manuscript. Ms. Huskey has full access to the data and takes responsibility for the integrity and accuracy of the data.

Conflict of Interest: The authors declare that they do not have any conflicts of interest.

Corresponding Author: Christina C. Wee, MD, MPH; Division of General Medicine and Primary Care, Department of Medicine, Beth Israel Deaconess Medical Center and Harvard Medical School, 330 Brookline Ave, Boston, MA 02215, USA (e-mail: cwee@bidmc.harvard.edu).

\section{REFERENCES}

1. Shekelle PG, et al. Pharmacological and surgical treatment of obesity. Evid Rep Technol Assess (Summ). 2004;(103):1-6.

2. Wee CC. A 52-year-old woman with obesity: review of bariatric surgery. JAMA. 2009;302(10):1097-104.

3. Nguyen NT, et al. Trends in use of bariatric surgery, 2003-2008. J Am Coll Surg. 2011;213(2):261-6.

4. Flegal KM, et al. Prevalence of obesity and trends in the distribution of body mass index among US adults, 1999-2010. JAMA. 2012.

5. Nguyen NT, et al. The relationship between hospital volume and outcome in bariatric surgery at academic medical centers. Ann Surg. 2004;240(4):586-93. discussion 593-4.

6. Santry HP, Gillen DL, Lauderdale DS. Trends in bariatric surgical procedures. JAMA. 2005;294(15):1909-17.

7. Sjostrom L, et al. Lifestyle, diabetes, and cardiovascular risk factors 10 years after bariatric surgery. N Engl J Med. 2004;351(26):2683-93.

8. O'Brien PE, et al. Systematic review of medium-term weight loss after bariatric operations. Obes Surg. 2006;16(8):1032-40.

9. Adams KF, et al. Overweight, obesity, and mortality in a large prospective cohort of persons 50 to 71 years old. N Engl J Med. 2006;355(8):763-78.

10. Flum DR, et al. Early mortality among medicare beneficiaries undergoing bariatric surgical procedures. JAMA. 2005;294(15): 1903-8.

11. Flum DR, et al. Perioperative safety in the longitudinal assessment of bariatric surgery. N Engl J Med. 2009;361(5):445-54.

12. Suter M, et al. Laparoscopic Roux-en-Y gastric bypass: significant longterm weight loss, improvement of obesity-related comorbidities and quality of life. Ann Surg. 2011;254(2):267-73.

13. Dixon JB, et al. Adjustable gastric banding and conventional therapy for type 2 diabetes: a randomized controlled trial. JAMA. 2008;299(3):316-23.

14. Schauer PR, et al. Bariatric surgery versus intensive medical therapy in obese patients with diabetes. N Engl J Med. 2012;366(17):1567-76.

15. Adams TD, et al. Health benefits of gastric bypass surgery after 6 years. JAMA. 2012;308(11):1122-31.

16. Thomas AM, et al. Perceptions of obesity: black and white differences. J Cult Divers. 2008;15(4):174-80.

17. Stevens J. Obesity and mortality in Africans-Americans. Nutr Rev. 2000;58(11):346-53.

18. Wee CC, et al. Obesity, race, and risk for death or functional decline among medicare beneficiaries: a cohort study. Ann Intern Med. 2011;154(10):645-55.

19. White MA, et al. Gender, race, and obesity-related quality of life at extreme levels of obesity. Obes Res. 2004;12(6):949-55.

20. Padgett J, Biro FM. Different shapes in different cultures: body dissatisfaction, overweight, and obesity in African-American and Caucasian females. J Pediatr Adolesc Gynecol. 2003;16(6):349-54.

21. Dorsey RR, Eberhardt MS, Ogden CL. Racial/ethnic differences in weight perception. Obesity (Silver Spring). 2009;17(4):790-5. 
22. Steffen $\mathbf{K J}$, et al. Blood alcohol concentrations rise rapidly and dramatically after Roux-en-Y gastric bypass. Surg Obes Relat Dis. 2013.

23. Clinical guidelines on the identification, evaluation, and treatment of overweight and obesity in adults-the evidence report. National Institutes of Health. Obes Res. 1998 Sep;6 Suppl 2:51S-209S.

24. Kolotkin RL, et al. Development of a brief measure to assess quality of life in obesity. Obes Res. 2001;9(2):102-11.

25. Nguyen NT, et al. Use and outcomes of laparoscopic versus open gastric bypass at academic medical centers. J Am Coll Surg. 2007;205(2):248-55.

26. Kolotkin RL, Crosby RD, Williams GR. Health-related quality of life varies among obese subgroups. Obes Res. 2002;10(8):748-56.
27. Caldwell MB, Brownell KD, Wilfley DE. Relationship of weight, body dissatisfaction, and self-esteem in African American and white female dieters. Int J Eat Disord. 1997;22(2):127-30.

28. Anderson WA, et al. Weight loss and health outcomes in African Americans and whites after gastric bypass surgery. Obesity (Silver Spring). 2007;15(6):1455-63.

29. DeMaria EJ, Portenier D, Wolfe L. Obesity surgery mortality risk score: proposal for a clinically useful score to predict mortality risk in patients undergoing gastric bypass. Surg Obes Relat Dis. 2007;3(2): 134-40.

\section{APPENDIX}

\section{PCP excluded 23}

1392 mailed recruitment letters

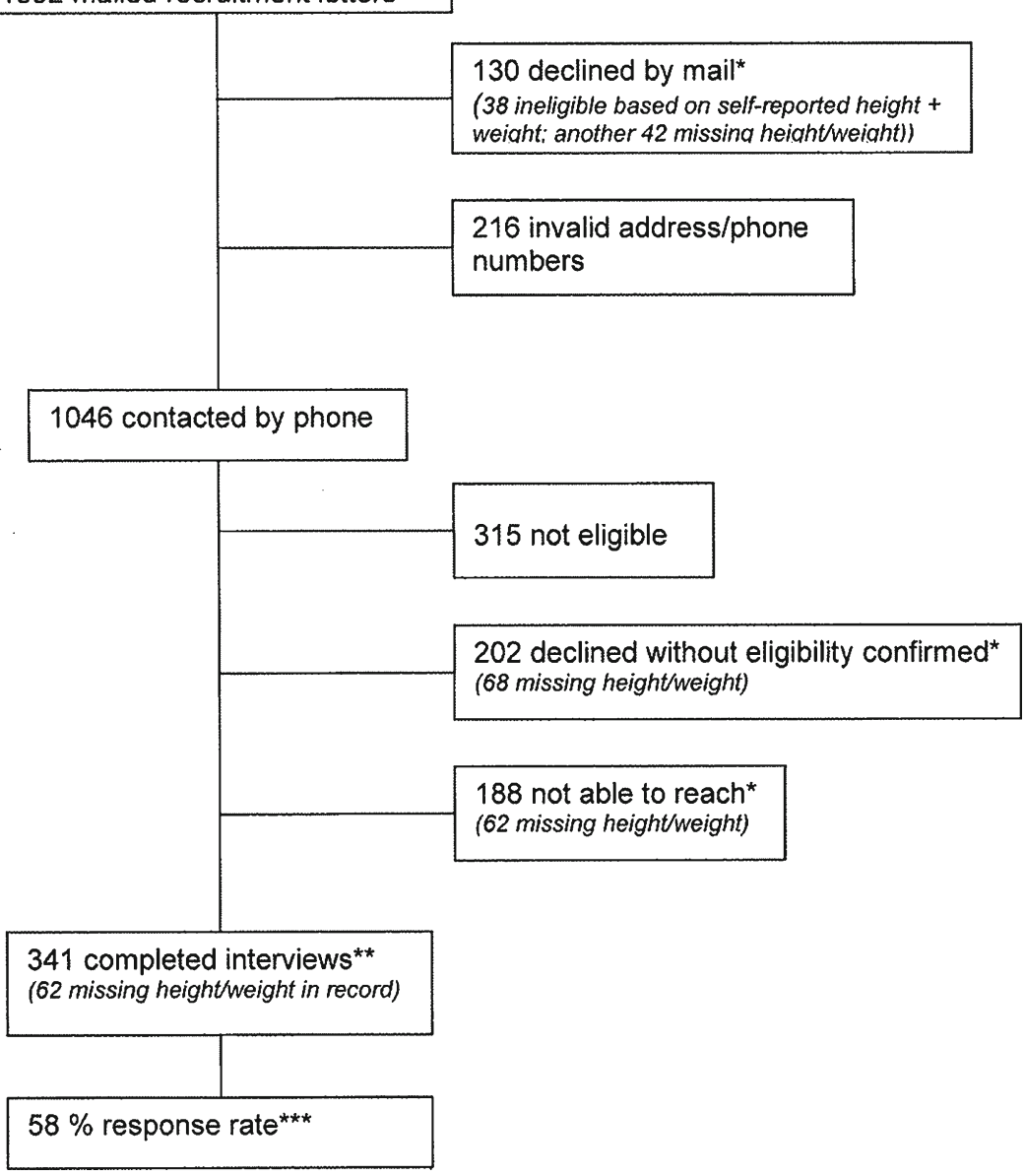

Figure 1. Recruitment of the primary care sample. (asterisk) The estimated probability of study eligibility is $29 \%$ among those without documented height/weight in record and $63 \%$ if documented. (dagger) Four participants were deemed ineligible after completing the interview leaving an analytical sample of 337. (double dagger) The calculated response rate accounts for probability of eligibility among those who declined based on whether they had a height and weight documented in the medical record. 